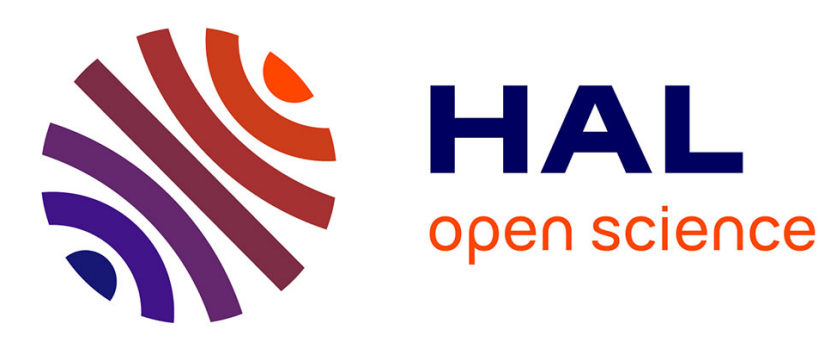

\title{
Infectious endocarditis in patients with cirrhosis of the liver: a model of infection in the frail patient
}

\author{
M. L. Fernández Guerrero, J. González López, M. Górgolas
}

\section{To cite this version:}

M. L. Fernández Guerrero, J. González López, M. Górgolas. Infectious endocarditis in patients with cirrhosis of the liver: a model of infection in the frail patient. European Journal of Clinical Microbiology and Infectious Diseases, 2010, 29 (10), pp.1271-1275. 10.1007/s10096-010-0998-8 . hal-00600039

\section{HAL Id: hal-00600039 \\ https://hal.science/hal-00600039}

Submitted on 13 Jun 2011

HAL is a multi-disciplinary open access archive for the deposit and dissemination of scientific research documents, whether they are published or not. The documents may come from teaching and research institutions in France or abroad, or from public or private research centers.
L'archive ouverte pluridisciplinaire HAL, est destinée au dépôt et à la diffusion de documents scientifiques de niveau recherche, publiés ou non, émanant des établissements d'enseignement et de recherche français ou étrangers, des laboratoires publics ou privés. 
Diseases

Editorial Manager(tm) for European Journal of Clinical Microbiology \& Infectious

Manuscript Draft

Manuscript Number: EJCMID-D-10-00196R1

Title: Infectious Endocarditis in Patients with Cirrhosis of the Liver: A Model of Infection in the Frail Patient

Article Type: Article

Keywords: infectious endocarditis, beta-hemolytic streptococci, cirrhosis of the liver.

Corresponding Author: Prof Manuel Luis Fernández Guerrero, M.D.

Corresponding Author's Institution: Fundación Jiménez Díaz

First Author: Manuel Luis Fernández Guerrero, M.D.

Order of Authors: Manuel Luis Fernández Guerrero, M.D.; Julio José Gonzalez Lopez, M.D.; Miguel Górgolas, M.D.

Abstract:

To know whether cirrhosis is a predisposing cause of IE and to determine the microbiology, prognosis and the role of cardiac surgery on mortality.

Review of cases of infectious endocarditis in a university-affiliated hospital during 10 years. Thirty-one(9.8\%) patients among 316 cases of infectious endocarditis had hepatic cirrhosis. Valve disorders were present in $62.2 \%$ of cirrhotic patients and infection occurred on aortic(48\%) and mitral valves(45\%).Endocarditis was hospital-acquired in $14(45 \%)$ and $11(17.7 \%)$ of cirrhotic and controls respectively(OR 3.82;95\%CI:1.46-9.99;p 0.005).Staphylococcus aureus was the most common causative microorganism but ßeta-hemolytic streptococci were most frequently isolated in cirrhotic patients(OR 8.75; 95\% CI: 1.7-45.2;p 0.001).Renal failure was more frequent in patients with cirrhosis(OR 8.23;95\%CI: 3.06-22.2; p 0.001).Cirrhotic patients had a higher mortality(51\% vs 17.7\%; OR 4.95;95\%CI:1.89-12.91;p 0.001) associated with the severity of liver disease. Valve replacement was performed less frequently in cirrhotic patients(56.2\% vs $92 \%)$ and the operative mortality was extremely high in patients with stages B and C.

Hepatic cirrhosis is a frequent comorbid condition in patients with endocarditis. Due to the presence severe hepatic dysfunction, cardiac surgery is not undertaken even when indicated and mortality is high in stages B and C. Endocarditis is a serious hazard for hospitalized cirrhotic patients.

Response to Reviewers:

Dear Dr. Van Belkum:

Thank you very much for the opportunity of revising the above mentioned manuscript. In doing the revision, I have taken into account all the suggestions of the reviewer.

Firstly, let me tell you why we chose to perform a case-control study instead of a case-cohort comparison. A case-control study is a simple and very useful investigative tool to identify factors that may contribute to the understanding of many medical conditions. In this case, we compared patients 
with cirrhosis of the liver and endocarditis with subjects with endocarditis but without such underlying disease. In short, we looked back to see if there were characteristics of these patients that differ from those who did not have cirrhosis. The main reasons of our choice were:

1. Simplicity.

2. Accuracy. Because patients were seen over a relatively long period -10 years- we tried to bring nearer cases and controls to avoid biases associated with changes in diagnostic techniques (use of TEE, blood cultures), antibiotic usage or surgical team over the time. For this reason we selected two controls for each case: the previous and the consecutive to the index case.

Reviewer:

1. Our patients with cirrhosis of the liver were not on any type of chronic antimicrobial therapy with fluoroquinolones or other agents such as those that are administered for the prevention of primary bacterial peritonitis. We have included a short comment on this in the last paragraph of page 7. This is an interesting comment because such intervention may eventually favour enterococcal infections. Our cases, enterococcal endocarditis mainly occurred as a result of urinary tract instrumentation. Patients with endocarditis caused by beta-hemolytic endocarditis developed the disease in the community and was not associated with a previous use of antibiotics.

2. As suggested, we have included a short summary of our results and a recommendation on the management of cirrhotic patients with endocarditis in the last paragraph of page 11.

In addition, one new quotation (no.13) has been included.

Thank you once more for this opportunity and do not hesitate if further questions are raised.

Looking forward to hearing from you.

Yours sincerely

Manuel L. Fernández Guerrero 
Infectious Endocarditis in Patients with Cirrhosis of the Liver:

\title{
A Model of Infection in the Frail Patient
}

\author{
Manuel L. Fernández Guerrero, M.D., Julio González López, M.D., \\ and Miguel Górgolas, M.D.. \\ Division of Infectious Diseases (Department of Medicine). \\ Fundación Jiménez Díaz. Universidad Autónoma de Madrid, Spain.
}

Running title: Infectious endocarditis in patients with hepatic cirrhosis.

Key words: Infectious endocarditis, liver cirrhosis, nosocomial endocarditis.

No conflicts of interest declared.

Corresponding author: Manuel L. Fernández Guerrero, M.D. ; Department of Medicine. Fundación Jiménez Díaz. Avda. Reyes Católicos, 2; 28040 Madrid, Spain.

Email: mlfernandez@,fjd.es

Phone: 34915504883

Fax: 34915504922 
Abstract

To know whether cirrhosis is a predisposing cause of IE and to determine the microbiology, prognosis and the role of cardiac surgery on mortality.

Review of cases of infectious endocarditis in a universityaffiliated hospital during 10 years.

Thirty-one $(9.8 \%)$ patients among 316 cases of infectious endocarditis had hepatic cirrhosis. Valve disorders were present in $62.2 \%$ of cirrhotic patients and infection occurred on aortic $(48 \%)$ and mitral valves(45\%).Endocarditis was hospital-acquired in $14(45 \%)$ and $11(17.7 \%)$ of cirrhotic and controls respectively(OR 3.82;95\%CI:1.46-9.99;p 0.005).Staphylococcus aureus was the most common causative microorganism but $\beta$ eta-hemolytic streptococci were most frequently isolated in cirrhotic patients(OR 8.75; 95\% CI: 1.7-45.2;p 0.001).Renal failure was more frequent in patients with cirrhosis(OR 8.23;95\%CI: 3.06-22.2; p 0.001).Cirrhotic patients had a higher mortality(51\% vs $17.7 \%$; OR 4.95;95\%CI:1.89-12.91;p 0.001) associated with the severity of liver disease. Valve replacement was performed less frequently in cirrhotic patients $(56.2 \%$ vs $92 \%)$ and the operative mortality was extremely high in patients with stages B and $\mathrm{C}$.

Hepatic cirrhosis is a frequent comorbid condition in patients with endocarditis. Due to the presence severe hepatic dysfunction, cardiac surgery is not undertaken even when indicated and mortality is high in stages B and C. Endocarditis is a serious hazard for hospitalized cirrhotic patients. 


\section{INTRODUCTION.}

Patients with cirrhosis of the liver are prone to develop severe bacterial infections due to the presence of various facilitating mechanisms including changes in the reticuloendothelial system, decreased opsonic activity, leukocyte dysfunction and iatrogenic factors among others [1]. Infections such as primary peritonitis, pneumonia, or tuberculosis are acknowledged causes of morbidity and mortality in patients with cirrhosis of the liver; yet, apart from these particular diseases, other infection issues have not been the subject of in-dept investigation [1].

Infectious endocarditis occurring in patients with hepatic cirrhosis is rarely reported [2]. Anecdotal case reports of endocarditis associated with invasive procedures - TIPS, upper endoscopy, sclerotherapy of esophageal varices or liver biopsy -, and caused by unusual pathogens comprise the majority of the articles [3-7]. However, to the best of our knowledge, studies have not analyzed the impact of liver cirrhosis, a common morbid condition, on the outcome of patients with endocarditis and thus, some important clinical and prognostic factors of endocarditis in patients with cirrhosis are still poorly known.

The aim of this study were: (i) to know whether cirrhosis is in fact a predisposing cause of IE; (ii) to determine the microbial etiology of IE in this population and other clinically relevant features; and (iii) to assess prognostic factors and how frequently cardiac surgery is needed and performed. 


\section{PATIENTS AND METHODS.}

Retrospective review of consecutive cases of infectious endocarditis in a tertiary, university affiliated hospital that provides service for a population of 350.000 people in downtown Madrid, during a period of 10 years (1998-2009). A control group composed of 2 patients per case (the previous and the consecutive to the index case) was used for comparison purposes.

Hepatic cirrhosis was diagnosed by clinical and laboratory criteria and in some patients by means of liver biopsy. The severity of liver dysfunction was categorized according to the modified Child-Turcotte-Pugh classification with a scoring system of 5 to 15 : scores of 5 and 6 being class A consistent with compensated cirrhosis; scores of 7 to 9 indicating class B characterized by mild ascitis and minimal encephalopathy; and scores of 10 to 15 class $\mathrm{C}$ with poorly controlled ascitis and severe hepatic encephalopathy [8]. The risk of postoperative mortality was assessed by the Model for End-stage Liver Damage (MELD) [9] with an on-line tool that used age, type of hepatic disease, the American Society of Anesthesiolologists Physical Status Classification (ASA score) and patient's laboratory values for serum bilirubin, serum creatinin and the international normalized ratio for prothrombin time (INR) [10].

IE was diagnosed by the usual modifed Duke's criteria [11]. Only patients with a definite diagnosis of endocarditis were included. Hospital-acquired infectious endocarditis was defined as endocarditis developing $\geq 72$ hours after admission in association 
with a hospital-based procedure or during another hospitalization within the preceding 8 weeks [7].

Renal failure was defined as an increase in serum creatinin levels $\geq 1.6 \mathrm{mg} / \mathrm{dl}$ persisting $\geq 24$ hours despite of the administration of fluids. Central nervous system complications included embolic events and brain hemorrhage and were evaluated by CT-scan and MR-imaging.

Mortality per episode was calculated. All death that occurred during hospitalization as a direct consequence of infection, including operative and perioperative mortality and any death associated with bleeding or acute liver failure occurring during the active phase of infection were considered related with endocarditis.

Statistics: SPSS v 11.0 (SPSS Inc., Chicago, IL) was used for the statistical analysis of the data. Continuous variables were expressed as mean (range). Discrete variables were expressed as percentages. Associations were tested by chi-square test or the Fisher exact test when samples were small. The strength of associations was measured by odds ratio (OR) or the Haldane estimator for small sample $2 \times 2$ tables, and their 95\% confidence interval (CI). Differences in continuous variables were measured by Student $t$ test for independent variables. Differences between groups were considered significant at $\mathrm{p}$ value $<0.05$. RESULTS.

Thirty-one (9.8\%) patients among 316 cases of infectious endocarditis had cirrhosis of the liver. The mean age of cirrhotic patients was 59.6 years, lower than that in the control group. Most 
patients $(71 \%)$ were males. The etiology of hepatic disease was alcoholic cirrhosis in 16 patients (51.6\%), posthepatitis cirrhosis caused by hepatitis $\mathrm{C}$ or $\mathrm{B}$ viruses in 11 patients $(35.4 \%)$ or cryptogenic cirrhosis in $4(13 \%)$ and were classified as stages A (12), B (8), C (11) of Child-Turcotte-Pugh.

Table 1 shows some relevant epidemiologic and clinical features of endocarditis in patients with cirrhosis of the liver. An underlying predisposing valve disease was present in $62.2 \%$ of cirrhotic patients and infection occurred mainly on aortic (48\%) and mitral valves (45\%). Infectious endocarditis was hospital-acquired in $14(45 \%)$ and $11(17.7 \%)$ of cirrhotic and control patients respectively (OR 3.82;95\% CI: 1.46-9.99 ; p 0.005). Central venous catheters (4 cases), urinary tract instrumentation (3 cases), colonoscopy (1 case), total parenteral nutrition (1 case), liver biopsy (1 case), sclerotherapy of esophageal varices (1) and SengstakenBlakemore balloon (1 case) were the recognized sources of bacteremia.

No differences were observed among cirrhotic and control patients in the relative frequency of complications such as cardiac failure or central nervous system events. However, renal failure was significantly more frequent in patients with cirrhosis of the liver (OR 8.23; 95\% CI: 3.06-22.2; p 0.001).

Table 2 shows the microbial etiology of infectious endocarditis in patients with cirrhosis of the liver. None of these patients were on chronic, low-dose antimicrobial therapy with fluoroquinolones or other drugs for prevention of primary bacterial peritonitis. 
Staphylococcus aureus was the most common causative microorganism in both cirrhotic and control patients. Beta-hemolytic streptococci, including $S$. agalactiae and $S$. pyogenes, were most frequently isolated in patients with cirrhosis of the liver than in controls (OR 8.75; 95\% CI: $1.7-45.2 ; \mathrm{p}$ 0.001). On the other hand, viridans streptococci were uncommonly found in cirrhotic patients (OR 0.1; 95\% CI: 0.010.83; p 0.002). Staphylococcus aureus (5), enterococci (4), coagulasenegative staphylococci (2), Escherichia coli (1), Candida albicans (1) and $P$ aeruginosa (1) were the microorganisms isolated in cirrhotic patients with nosocomial endocarditis.

Sixteen patients (51\%) with cirrhosis of the liver and 11 $(17.7 \%)$ in the control group died during hospitalization for causes associated with endocarditis (OR 4.95;95\% CI: 1.89-12.91; p 0.001). Mortality was associated with the severity of liver disease and so, while only 2 of $12(16.6 \%)$ patients in stage A died, 6 out of $8(75 \%)$ in stage $\mathrm{B}$ and 8 of $11(72.7 \%)$ in stage C died. Cardiac failure, hepato-renal syndrome with acute renal failure and brain bleeding were the most common causes of death.

Valve replacement was considered in 16 patients with cirrhosis of the liver who developed cardiac failure but was performed in only $9(56.2 \%)$ cases in whom it seemed feasible and indicated. Five of theses patients survived ( 4 in stage $A$, and 1 in stage $B$ ) and 4 died (3 in stage $\mathrm{B}$ and 1 in stage $\mathrm{C}$ ). The calculated postoperative mortality risk of these last patients ranged from $57 \%$ to $80 \%$ at 30 days and from $69 \%$ to $81 \%$ at 1 -year. In the rest of the cases, valve replacement was declined due to the presence of end-stage liver 
failure ( 3 in stage B, 4 in stage $C$ ). The postoperative mortality risk in this group of patients was retrospectively calculated and ranged from $33 \%$ to $85 \%$ at 30 days and from $54 \%$ to $91 \%$ at 1 -year. On the other hand, valve replacement was indicated in 24 control patients and was performed in $22(91.6 \%)$ of whom $18(81.8 \%)$ survived the infection.

\section{DISCUSSION.}

Cirrhosis of the liver was a common underlying condition in patients with IE observed in almost $10 \%$ of cases. Cirrhotic patients, particularly those with advanced disease exhibit leukocyte dysfunction and phagocytic defects that make them prone to develop focal and systemic bacterial infections. The presence of portosystemic shunts and the common occurrence of cutaneous abrasions in oedematous legs are potential sources of bacteremia from gastrointestinal tract and skin. In addition, patients with hepatic cirrhosis are frequently admitted to hospital where they are the subject of invasive diagnostic and therapeutic procedures with the potential of producing bacteremia and endocarditis.

In this series, endocarditis was a nosocomial infection in $45 \%$ of cases, a proportion significantly higher than that found in the control group and much higher than that observed in previous reports on hospital-acquired infectious endocarditis [7,12]. This observation suggests that infectious endocarditis is a serious hazard for hospitalized patients with cirrhosis of the liver. As shown in previous studies, venous catheters and urinary tract instrumentation were the main sources for bacteremia leading to endocarditis in 
cirrhotic patients [13]. However it is interesting to note that other procedures that are commonly undertaken in these patients such as liver biopsy or urgent measures for the control of esophageal bleeding such as sclerotherapy of varices and Sengstaken-Blakemore balloon tamponade may be associated with bacteremia and endocarditis.

While $S$ aureus and enterococci were the organisms most frequently found in nosocomial cases, $\beta$-hemolytic streptococci were common causes of community-acquired endocarditis in patients with cirrhosis. In previous studies, endocarditis caused by $\beta$-hemolytic streptococci has been associated with chronic underlying diseases such as alcoholism and cirrhosis of the liver [14]. Specifically $S$ agalactiae, that in pre- and early antibiotic era was almost exclusively an infection seen in postpartum and postabortal women, is now a microrganism causing severe infections, including bacteremia and endocarditis, in chronically ill patients with cirrhosis of the liver, malignancies and some other conditions [14,15]. As noted before, endocarditis caused by $S$ agalactiae followed a complicated course characterized by large vegetations, rapid destruction of cardiac valves and heart failure $[15,16]$. In addition, chronic liver disease has been recognized as a predisposing factor for $S$ bovis bacteremia which may explain the increased frequency of endocarditis caused by these microorganisms in our series [17].

Liver cirrhosis has a significant impact on the mortality of patients with bacteremic infections and high production of proinflammatory cytokines seems to play a role in the worsening of 
liver function and the development of organ-system failures such as hepato-renal syndrome or hepatic encephalopathy [18,19]. Remarkably, renal failure occurred in most of our cases and seemed to contribute to the poor outcome of patients. Besides heart failure, acute renal failure was a major determinant of mortality.

Mortality of cardiac surgery of patients with advanced liver cirrhosis is extremely high [20] and so, the decision to operate on these patients is difficult. In this series, although indicated in most patients with cardiac failure, valve replacement was precluded in many due to the presence of end-stage liver disease and when performed, only patients in good functional state survived. MELD score, which has been recently validated to quantify the risk of mortality postoperatively in patients with cirrhosis, may be a useful tool in the task of deciding whether or not these patients must been sent to the operating room for valve replacement [21].

In summary, we show herein data that suggest that infectious endocarditis in patients with cirrhosis of the liver is a severe disease with unique community-acquired etiologic agents. Besides, infectious endocarditis is frequently acquired during hospitalization as a consequence of invasive diagnostic or therapeutic procedures. When indicated, valve replacement can be successfully performed in patients with minor or mild hepatic dysfunction. However, operative mortality of patients with Child stages $\mathrm{B}$ and $\mathrm{C}$ is extremely high and probably should be undertaken only in selected individuals with cardiac failure without renal failure and other systemic complications. 
Finally, because most of the factors facilitating the development of bacterial infections in cirrhotic patients are unchangeable and many cases occur during hospitalization, prevention should focus on measures to avoid bacteremia and other nosocomial infections. New studies are required to better determine the role of cardiac surgery in the management of infectious endocarditis in cirrhotic patients. 


\section{References}

1.- Christou L, Pappas G, Falagas ME. Bacterial infection-related morbidity and mortality in cirrhosis. Am J Gastroenterol 2007;102:1510-17.

2.- McCashland TM, Sorrel MF, Zetterman RK. Bacterial endocarditis in patients with chronic liver disease. Am J Gastroenterol 1994;89:924-7.

3.- Finkielman JD, Gimenez M, Pietrangelo C, Blanco MV. Endocarditis as a complication of a transjugular intrahepatic portosystemic stent-shunt. Clin Infect Dis 1996;22:385-6.

4.- Schalaeffer F, Riesenberg K, Mikolich D, Sikuler E, Niv Y. Serious bacterial infections after endoscopic procedures. Arch Intern Med 1996;156:572-4.

5.- Tripodi MF, Adinolfi LE, Ragone E, et al. Streptococcus bovis endocarditis and its association with chronic liver disease: an underestimated risk factor. Clin Infect Dis 2004; 15:1394-400.

6.- Fayad G, Modine T, Mokhtari S et al. Pasteurella multocida aortic valve endocarditis: case report and literature review. J Heart Valve Dis 2003;12:261-3.

7.- Fernández Guerrero ML, Verdejo C, Azofra J, Górgolas M. Hospital-acquired infectious endocarditis not associated with cardiac surgery: an emerging problem. Clin Infect Dis 1995;20:16-23.

8.- Pugh RN, Murray-Lyon IM, Dawson JL et al. Transection of the oesophagus for bleeding oesophageal varices. Br J Surg 1973;60:646 
9.- Kamath PS, Wiesner RH, Gordon FD et al. A model to predict survival in patients with end-stage liver disease. Hepatology $2001 ; 33: 464$

\section{0.- www.mayoclinic.org/meld/mayomodel9.html}

11.- Li JS, Sexton DJ, Mick N, et al. Proposed modifications to the Duke criteria for the diagnosis of infective endocarditis. Clin Infect Dis 2000;30:633-8.

12.- Benito N, Miró JM, de Lazzari E, et al. Health care-associated native valve endocarditis: importance of non-nosocomial acquisition. Ann Intern Med 2009;150:586-94.

13.- Fernández Guerrero ML, Herrero D, Bellver MT, Gadea I, Fernández Roblas R, Górgolas M. Nosocomial enterococcal endocarditis: a serious hazard for hospitalized patients with enterococcal bacteremia. Journal of Internal Medicine 2002;252:510515.

14.- Lefort A, Lortholary O, Casassus P, Selton-Sutty C, Guillevein L, Mainardi JL and the Beta-hemolytic streptococci infective endocarditis study group. Comparison between adult endocarditis due to beta-hemolytic streptococci (serogroups A, B, C, and G) and Streptococcus milleri: a multicenter study in France. Arch Intern Med 2002;162:2450-6.

15.- Sambola A, Miro JM, Tornos P, et al. Streptococcus agalactiae infective endocarditis: analysis of 30 cases and review of the literature, 1962-1998. Clin Infect Dis 2002;34:1576-84. 
16.- Rollan MJ, SanRoman JA, Vilacosta I, Sarria C, Lapez J, Acuña M, Bratos JL. Clinical profile of Streptococcus agalactiae native valve endocarditis. Am Heart J 2003;146:1095-8.

17.- Gonzalez Quintela A, Martínez C, Castroagudín JF, Rajo MC, Domínguez MJ. Prevalence of liver disease in patients with Streptococcus bovis bacteremia. J Infect 2001;42:116-9.

18.- Gustot T, Durand F, Lebrec D, Vincent JL, Moreau R. Severe sepsis in cirrhosis. Hepatology 2009;50:2022-33.

19.- Chen SY, Tsai CL, Lin CH, Lee CC, Chiang WC, Wang JL, Ma MH, Chen SC, Chen WJ, Chang SC. Impact of liver cirrhosis on mortality in patients with community-acquired bacteremia. Diagn Microbiol Infect Dis 2009;64(2):124-30.

20.- Takahashi M, Li TS, Ikeda H, Mikamo A, Hamano K. Succesful aortic valve replacement for infective endocarditis in a patient with severe liver cirrhosis. Ann Thorac CardiovascSurg 2006;12:287-9 21.- Teh SH, Nagorney DM, Stevens SR, et al. Risk factors for mortality after surgery in patients with cirrhosis. Gastroenterology 2007;132:1261-9. 
Table 1. Epidemiologic, Clinical Features and Mortality of Infectious Endocarditis in Patients with Cirrhosis of the Liver.

\begin{tabular}{|c|c|c|c|c|}
\hline & & Patients $\mathrm{n}$ & $10(\%)$ & \\
\hline & Cirrhosis & Control & OR;95\%CI & $p$ \\
\hline Mean age & $59.6(32-71)$ & $68.9(45-86)$ & & \\
\hline Gender: Male & $22(70.9)$ & $41(66.1)$ & & \\
\hline Female & $9(29.19)$ & $21(33.8)$ & & \\
\hline $\begin{array}{l}\text { Underlying valve disease } \\
\text { Rheumatic disease } \\
\text { Degenerative } \\
\text { Prosthetic valve } \\
\text { Mi valve prolapse } \\
\text { Other } \\
\text { Undetermined }\end{array}$ & $\begin{array}{c}5(16.1) \\
6(19.3) \\
4(12.9) \\
3(9.6) \\
1(3.2) \\
12(38.7)\end{array}$ & $\begin{aligned} 9 & (14.5) \\
16 & (25.8) \\
10 & (16.1) \\
3 & (4.8) \\
7 & (11.2) \\
17 & (27.4)\end{aligned}$ & & ns \\
\hline $\begin{array}{l}\text { Valve involvement } \\
\text { Mitral valve } \\
\text { Aortic valve } \\
\text { Mi \& Ao valves } \\
\text { Tricuspid valve } \\
\text { Other* }\end{array}$ & $\begin{array}{l}14(45.1) \\
15(48.3) \\
2 \\
\quad- \\
\quad-\end{array}$ & $\begin{array}{l}25(40.3) \\
23(37) \\
3 \\
9 \\
2\end{array}$ & 0.09:0.01-1.59 & .03 \\
\hline $\begin{array}{l}\text { Acquisition } \\
\text { Hospital-acquired } \\
\text { Community-acquired }\end{array}$ & $\begin{array}{l}14(45.1) \\
17(54.8)\end{array}$ & $\begin{array}{c}11(17.7) \\
51(82.2)\end{array}$ & $3.82 ; 1.46-9.99$ & .005 \\
\hline $\begin{array}{l}\text { Complications } \\
\text { Cardiac failure } \\
\text { Brain emboli } \\
\text { Renal failure }\end{array}$ & $\begin{array}{c}16(51.6) \\
5(16) \\
19(61.2)\end{array}$ & $\begin{array}{l}25(40.3) \\
10(16.1) \\
10(16.1)\end{array}$ & $8.23 ; 3.06-22.2$ & .001 \\
\hline Mortality & 16 (51.6) & $11(17.7)$ & $4.95 ; 1.89-12.91$ & .001 \\
\hline
\end{tabular}


Table 2. Microbial Etiology of Infectious Endocarditis In Patients with Cirrhosis of the Liver.

\section{Patients no $(\%)$}

\section{Hepatic cirrhosis Controls OR;95\%CI $p$}

(31)

\begin{tabular}{|c|c|c|c|c|}
\hline Staphylococcus aureus & $8(25.8)$ & $17(27.4)$ & & ns \\
\hline Coagulase- staphylococci & $2(6.4)$ & $5(8.6)$ & & ns \\
\hline Enterococci & $6(19.3)$ & $6(9.6)$ & & ns \\
\hline$\beta$-hemolytic streptococci: & $7(22.5)$ & $2(3.2)$ & $8.75 ; 1.7-45.2$ & .001 \\
\hline$S$ agalactiae & 4 & 1 & & \\
\hline Spyogenes & 3 & - & & \\
\hline Group C streptococci & - & 1 & & \\
\hline Streptococcus bovis & $3(9.6)$ & $3(4.8)$ & & \\
\hline Streptococcus pneumoniae & 1 & - & & \\
\hline Streptococcus viridans & $1(3.2)$ & $15(24.1)$ & $0.1 ; 0.01-0.83$ & .002 \\
\hline Listeria monocytogenes & 1 & 1 & & \\
\hline Gram-negative bacteria* & $1(3.2)$ & $6(9.6)$ & & \\
\hline Fungi & 1 & 1 & & \\
\hline Coxiella burnetii & - & 3 & & \\
\hline Unknown & - & 3 & & \\
\hline
\end{tabular}

* HACEK group, Enterobacteriaceae, Psendomonas. 
Ref. EJCMID-D-10-00196 "Infectious Endocarditis in Patients with Cirrosis of the Liver:A Model of Infection in the Frail Patient".

Dear Dr. Van Belkum:

Thank you very much for the opportunity of revising the above mentioned manuscript.

In doing the revision, I have taken into account all the suggestions of the reviewer.

Firstly, let me tell you why we chose to perform a case-control study instead of a case-cohort comparison. A case-control study is a simple and very useful investigative tool to identify factors that may contribute to the understanding of many medical conditions. In this case, we compared patients with cirrhosis of the liver and endocarditis with subjects with endocarditis but without such underlying disease. In short, we looked back to see if there were characteristics of these patients that differ from those who did not have cirrhosis. The main reasons of our choice were:

1. Simplicity.

2. Accuracy. Because patients were seen over a relatively long period -10 years- we tried to bring nearer cases and controls to avoid biases associated with changes in diagnostic techniques (use of TEE, blood cultures), antibiotic usage or surgical team over the time. For this reason we selected two controls for each case: the previous and the consecutive to the index case.

Reviewer:

1. Our patients with cirrhosis of the liver were not on any type of chronic antimicrobial therapy with fluoroquinolones or other agents such as those that are administered for the prevention of primary bacterial peritonitis. We have included a short comment on this in the last paragraph of page 7 . This is an interesting comment because such intervention may eventually favour enterococcal infections. Our cases, enterococcal endocarditis mainly occurred as a result of urinary tract instrumentation. Patients with endocarditis caused by beta-hemolytic endocarditis developed the disease in the community and was not associated with a previous use of antibiotics.

2. As suggested, we have included a short summary of our results and a recommendation on the management of cirrhotic patients with endocarditis in the last paragraph of page 11.

In addition, one new quotation (no.13) has been included. 
Thank you once more for this opportunity and do not hesitate if further questions are raised.

Looking forward to hearing from you.

Yours sincerely

Manuel L. Fernández Guerrero 